\title{
Biotic stress in plants: life lessons from your parents and grandparents
}

\author{
A. E. Dorantes-Acosta ${ }^{1}$, C. V. Sánchez-Hernández ${ }^{2}$ and M. A. Arteaga-Vázquez ${ }^{1 *}$ \\ ${ }^{1}$ Laboratorio de Epigenética y Biología del Desarrollo, Instituto de Biotecnología y Ecología Aplicada (INBIOTECA), Universidad Veracruzana. Xalapa, Veracruz. \\ México \\ ${ }^{2}$ Departamento de Producción Agrícola, Centro Universitario de Ciencias Biológicas y Agropecuarias, Universidad de Guadalajara, Guadalajara, Jalisco, Mexico \\ *correspondence: maarteaga@uv.mx
}

Edited by:

Bernie Carroll, The University of Queensland, Australia

Reviewed by:

Bernie Carroll, The University of Queensland, Australia

Epigenetic regulation is essential for growth and development in eukaryotic organisms (Henikoff et al., 2008; Suzuki and Bird, 2008) and is also responsible for the establishment, maintenance, and reversal of non-genetic cellular memory that records developmental and environmental cues, including those arising from biotic and abiotic stress (Bonasio et al., 2010). A series of recent stimulating papers, show that biotic stress can trigger a transgenerational epigenetic response in plants, where DNA methylation seems to play a central role.

Plants sense and respond to environmental cues by a repertoire of mechanisms that regulate gene expression in order to maximize chances of survival in hostile environments. In addition to preformed defense traits, plants have evolved inducible defenses against microbial pathogens, herbivores, and even other plants that involve the regulation of gene expression for the synthesis of defensive secondary metabolites and specific proteins (Walling, 2000; Howe and Jander, 2008; Mithofer and Boland, 2012). Plants rely on the innate immunity of each cell and on systemic signals emanating from infection sites (Jones and Dangl, 2006). Plant hormones play essential roles during systemic defense signaling (RobertSeilaniantz et al., 2011). Salicylic acid (SA) primarily triggers resistance against biotrophic and hemibiotrophic pathogens whereas a combination of jasmonic acid (JA) and ethylene (ET) signaling activates resistance against necrotrophic pathogens (Glazebrook, 2005; Robert-Seilaniantz et al., 2011). SA acts as an endogenous signal involved in systemic acquired resistance (SAR), an inducible resistance against a broad spectrum of pathogens including viruses, bacteria, and fungi that cause necrosis through rapid programmed cell death of infected cells, known as the hypersensitive response (Durrant and Dong, 2004). SAR induces resistance in the systemic (uninoculated) plant organs in response to local infection (Vlot et al., 2009). Recent evidence shows that NON-EXPRESSOR of PATHOGENESISRELATED GENES 3 (NPR3) and NPR4 are SA receptors that bind SA with different affinities and regulate degradation of the transcription cofactor NPR1 in a SA-dependent manner (Fu et al., 2012).

In addition to their role during plant development, JA and JA-related compounds, including methyl-jasmonate (MeJA) and jasmonate-isoleucine conjugate (JA-Ile), play essential roles during endogenous regulation of plant resistance to mechanical wounding and herbivory by modulating global changes in gene expression (Creelman and Mullet, 1997; Sheard et al., 2010). Priming (or sensitization) refers to the enhanced ability for the quicker and more effective activation of specific cellular defense responses upon previous exposure to biotic or abiotic stress (Conrath et al., 2002, 2006). Defense pathways and priming can also be induced by application of chemical stimuli including the non-protein amino acid beta-amino-butyric acid (BABA) (Zimmerli et al., 2000). In addition to plant hormones, small RNAs and genes involved in the biogenesis of small RNAs are also components of the plant defense strategies against herbivory and microbial pathogens (Pandey et al., 2008; RuizFerrer and Voinnet, 2009; Katiyar-Agarwal and Jin, 2010).
Here we comment on a series of papers that provide evidence on transgenerational epigenetic effects during biotic stress. Rasmann et al. (2012) report transgenerational priming responses (TPR) in tomato and Arabidopsis induced by caterpillar herbivory (Helicoverpa zea and Pieris rapae) and application of MeJA. TPR results in a reduction of up to $\sim 40 \%$ in caterpillar weight gain and this effect persists after one stress free generation in Arabidopsis (Rasmann et al., 2012). Experiments with the coronatine insentitive1 (coil-1) and the triple dicerlike2/dicer-like3/dicer-like4 (dcl2/dcl3/dcl4) mutants show that the TPR depends on JA perception and on components of the RNA-dependent DNA methylation pathway involved in de novo DNA methylation (RdDM) (Law and Jacobsen, 2010; Rasmann et al., 2012).

In order to assay transgenerational effects in response to the biotrophic pathogen Pseudomonas syringae pv tomato DC3000 (PstDC3000) in Arabidopsis, Luna et al. (2012) recurrently inoculated a set of parental lines (P0) with increasing doses of PstDC3000. Fitness of progeny (P1) from PstDC3000 infected plants did not differ statistically from control plants progeny (C1) (Luna et al., 2012). However, P1 plants showed a statistically significant reduction in the colonization and disease symptoms after inoculation with: (1) the oomycete pathogen Hyaloperonospora arabidopsidis and (2) PstDC3000-lux (a bioluminescent strain of PstDC3000). Once established, this TPR can be maintained over one stress-free generation. Similar experiments employing parental lines in an nprl-1 mutant background showed that colonization reduction by 
$H$. arabidopsidis depends on a functional NPR1 gene. Consistent with an NPR1-dependent priming of SA-inducible defense, a faster and stronger induction of SA-inducible defense genes such as PATHOGENESIS-RELATED GENE 1 (PR1), WRKY6, WRKY53, and WRKY70 was also observed in P1 plants (Luna et al., 2012). Antagonistic effects between JA and SA pathways were confirmed by inoculating P1 plants with the nectrotrophic fungus Alternaria brassicicola (an inducer of JA-dependent defense response). P1 plants contained similar endogenous levels of JA, JA-Ile, JA-precursor, and SA to C1 plants, but showed increased hyphal colonization and a reduction in the expression of JA-inducible genes, including PLANT DEFENSINE 1.2 (PDF1.2). The priming effects on SA and JA inducible genes correlate with the NPR1-dependent deposition of epigenetic marks characteristic of active chromatin (H3K9ac; acetylation of Lys-9 on Histone 3) in the case of PR-1, WRKY6 and WRKY53; and repressive chromatin (H3K27me3; trimethylation of Lys-27 on Histone 3) in the case of PDF1.2. Although a role for chromatin modifications mediating the TPR wasn't ruled out, assays with the domains rearranged methyltransferase 1 and 2/cytosine methyltransferase 3 (drm1/drm2/cmt3) triple mutant, affected in DNA methylation, showed that this mutants mimics the TPR observed in P1 plants and indicates that components of the RdDM pathway are required for TPR (Luna et al., 2012).

Similar experiments from Slaughter et al. (2012) using either BABA or an avirulent $P$ st strain also showed a TPR against PstDC3000 and $H$. arabidopsidis, and an IBS1 (IMPAIRED BABA-INDUCED STERILITY RESPONSE 1)-dependent increased expression of $P R 1, P R 2$, and $P R 5$. However, in sharp contrast to Luna et al. and Rasmann et al., the TPR was only maintained in the immediate progeny which might be the result of differences in experimental approaches (recurrent vs. single inoculation/stimulation) or actually represent biological differences in the molecular mechanism(s) involved (Slaughter et al., 2012).

High resolution genomewide profiling of the DNA methylation landscape in Arabidopsis from Dowen et al. (2012) shows that global disruption of establishment and maintenance of DNA methylation in a set of mutants including drm1/drm2/cmt3 and methyltransferase 1 (met 1 ) enhances resistance to bacteria and induces widespread dynamic changes in methylation. Distinct patterns of differentially methylated regions (DMR) can be observed when wild type plants are exposed to SA or either virulent or avirulent Pst strains. SA treatment uncovered a class of 21-nt siRNAs particularly evident at transposable elements (TEs)-associated DMRs and in many cases, SA-induced DMR associate with reprogramming of TEs and neighboring genes (Dowen et al., 2012).

Taken together, this set of papers unveiled a TPR during biotic stress in plants where DNA methylation and components of the RdDM pathway play a major role. Some open questions: what is the molecular nature of the TPR signal? What cells are responsible for sensing and transmitting the biotic stress memory? What is the impact of plant's age and intensity of the biotic stress on the TPR? Can the TPR behave as a paramutationlike phenomena?

\section{REFERENCES}

Bonasio, R., Tu, S., and Reinberg, D. (2010). Molecular signals of epigenetic states. Science 330, 612-616.

Conrath, U., Beckers, G. J., Flors, V., Garcia-Agustin, P., Jakab, G., Mauch, F., et al. (2006). Priming: getting ready for battle. Mol. Plant Microbe Interact. 19, 1062-1071.

Conrath, U., Pieterse, C. M., and Mauch-Mani, B. (2002). Priming in plant-pathogen interactions. Trends Plant Sci. 7, 210-216.

Creelman, R. A., and Mullet, J. E. (1997). Biosynthesis and action of jasmonates in plants. Annu. Rev. Plant Physiol. Plant Mol. Biol. 48, 355-381.

Dowen, R. H., Pelizzola, M., Schmitz, R. J., Lister, R., Dowen, J. M., Nery, J. R., et al. (2012). Widespread dynamic DNA methylation in response to biotic stress. Proc. Natl. Acad. Sci. U.S.A. 109, E2183-E2191.

Durrant, W. E., and Dong, X. (2004). Systemic acquired resistance. Annu. Rev. Phytopathol. 42, 185-209.

Fu, Z. Q., Yan, S., Saleh, A., Wang, W., Ruble, J., Oka, N., et al. (2012). NPR3 and NPR4 are receptors for the immune signal salicylic acid in plants. Nature 486, 228-232.

Glazebrook, J. (2005). Contrasting mechanisms of defense against biotrophic and necrotrophic pathogens. Annu. Rev. Phytopathol. 43, 205-227.

Henikoff, S., Strahl, B. D., and Warburton, P. E. (2008). Epigenomics: a roadmap to chromatin. Science 322, 853

Howe, G. A., and Jander, G. (2008). Plant immunity to insect herbivores. Annu. Rev. Plant Biol. 59, 41-66.
Jones, J. D., and Dangl, J. L. (2006). The plant immune system. Nature 444, 323-329.

Katiyar-Agarwal, S., and Jin, H. (2010). Role of small RNAs in host-microbe interactions. Annu. Rev. Phytopathol. 48, 225-246.

Law, J. A., and Jacobsen, S. E. (2010). Establishing, maintaining and modifying DNA methylation patterns in plants and animals. Nat. Rev. Genet. 11, 204-220.

Luna, E., Bruce, T. J., Roberts, M. R., Flors, V., and Ton, J. (2012). Next-generation systemic acquired resistance. Plant Physiol. 158, 844-853.

Mithofer, A., and Boland, W. (2012). Plant defense against herbivores: chemical aspects. Annu. Rev. Plant Biol. 63, 431-450.

Pandey, S. P., Shahi, P., Gase, K., and Baldwin, I. T. (2008). Herbivory-induced changes in the smallRNA transcriptome and phytohormone signaling in Nicotiana attenuata. Proc. Natl. Acad. Sci. U.S.A. 105, 4559-4564.

Rasmann, S., De Vos, M., Casteel, C. L., Tian, D., Halitschke, R., Sun, J. Y., et al. (2012). Herbivory in the previous generation primes plants for enhanced insect resistance. Plant Physiol. 158, 854-863.

Robert-Seilaniantz, A., Grant, M., and Jones, J. D. (2011). Hormone crosstalk in plant disease and defense: more than just jasmonate-salicylate antagonism. Annu. Rev. Phytopathol. 49, 317-343.

Ruiz-Ferrer, V., and Voinnet, O. (2009). Roles of plant small RNAs in biotic stress responses. Annu. Rev. Plant Biol. 60, 485-510.

Sheard, L. B., Tan, X., Mao, H., Withers, J., BenNissan, G., Hinds, T. R., et al. (2010). Jasmonate perception by inositol-phosphate-potentiated COI1-JAZ co-receptor. Nature 468, 400-405.

Slaughter, A., Daniel, X., Flors, V., Luna, E., Hohn, B., and Mauch-Mani, B. (2012). Descendants of primed Arabidopsis plants exhibit resistance to biotic stress. Plant Physiol. 158, 835-843.

Suzuki, M. M., and Bird, A. (2008). DNA methylation landscapes: provocative insights from epigenomics. Nat. Rev. Genet. 9, 465-476.

Vlot, A. C., Dempsey, D. A., and Klessig, D. F. (2009). Salicylic acid, a multifaceted hormone to combat disease. Annu. Rev. Phytopathol. 47, 177-206.

Walling, L. L. (2000). The myriad plant responses to herbivores. J. Plant Growth Regul. 19, 195-216.

Zimmerli, L., Jakab, G., Metraux, J. P., and MauchMani, B. (2000). Potentiation of pathogen-specific defense mechanisms in Arabidopsis by beta -aminobutyric acid. Proc. Natl. Acad. Sci. U.S.A. 97, 12920-12925.

Received: 10 September 2012; accepted: 31 October 2012; published online: 06 December 2012.

Citation: Dorantes-Acosta AE, Sánchez-Hernández CV and Arteaga-Vázquez MA (2012) Biotic stress in plants: life lessons from your parents and grandparents. Front. Gene. 3:256. doi: 10.3389/fgene.2012.00256

This article was submitted to Frontiers in Plant Genetics and Genomics, a specialty of Frontiers in Genetics. Copyright (C) 2012 Dorantes-Acosta, SánchezHernández and Arteaga-Vázquez. This is an open-access article distributed under the terms of the Creative Commons Attribution License, which permits use, distribution and reproduction in other forums, provided the original authors and source are credited and subject to any copyright notices concerning any third-party graphics etc. 